\title{
The long pause and the last pulse: Mapping East Polynesian colonisation
}

\author{
Tim Thomas \\ Anthropology Department, University of Otago, New Zealand \\ tim.thomas@otago.ac.nz
}

\section{Introduction}

Maps are rarely neutral depictions of space. They encode, simplify and abstract human experiences of landscapes according to particular needs and histories. More often than not, they are arguments - about how we should perceive the world in particular contexts (Wood 1992). Accordingly, maps are socially and culturally embedded. European maps, for example, have been identified as embodying the post-Cartesian Enlightenment project - a means of inquiry, examination and control, promoting the 'rational' utilisation of space (Tilley 1994:21) and thus a tool of imperialist and colonial practice (Carter 1987). In contrast, Marshall Islands navigation charts are more personal, indexing wave swells formed around islands as experienced by an individual canoe pilot/mapper - a kinaesthetic cartography, perhaps, far from the visuality and mathematics of the Cartesian map, but politicised, too, by social restrictions of ritual and access (Winckler 1901). The map is not the territory (Bateson 1972:460), but rather a purposedriven model.

Accepting maps as models enables us to explore them as visual representations of the human experience of movement in particular landscapes. We can be freed somewhat from the constraints of depicting pure geography by recognising that experiences of geography are never pure - they are mediated by technology, past experience, economic considerations and so on. The perception of distance, for example, is heavily mediated by modes of travel (whether one swims, takes a boat, or takes an aeroplane), the conditions of the terrain (a sheltered bay, a current-riven sea), and the attractiveness of the destination. The effect is to increase or decrease friction to movement, causing distance to be measured by effort, time and desire. What would a map look like if it could take such factors into consideration? In this paper, I explore this question by addressing debates about the pattern and pace of the prehistoric colonisation of East Polynesia through a series of analyses that model the geography of the Pacific as just such a 'friction landscape'.

My central focus is the long-standing problem of the 'long pause' in eastward migration after the Lapita-era colonisation of the Fiji-Samoa-Tonga region, before a belated last pulse of 
movement into East Polynesia. Recent academic debate has mostly focused on determining the duration of this pause, but this has also frequently required forays into determining cause. Here, I concentrate on the latter issue, but first, some background to the former will be necessary.

\section{Mapping East Polynesian colonisation}

Te Rangi Hiroa (Buck 1954) famously depicted the origin and culture of Polynesians as an octopus (Tangaroa) centred on the Society Islands, its tentacles snaking out over the map (Figure 1). The image reflects the importance of comparative ethnology and cosmology as evidence for early scholars and is of interest for its identification of Ra'iatea as the homeland (Havai'i) of Polynesian cultural development after migrations through Micronesia. It stands in contrast to an altogether more modernist map (Figure 2) first drawn by Emory and Sinoto (1965), but appearing in several subsequent publications (e.g. Jennings 1979). With the advent of stratigraphic excavation and radiocarbon dating, narratives of Polynesian origins increasingly stressed a stepwise progression of island-hopping migrations - leaving behind the timelessness and unity evident in Hiroa's map, and depicting instead a series of developmental pauses punctuated by sudden voyages of colonisation.

In what came to be known and critiqued as the 'authorised version' (Irwin 1981) or 'orthodox scenario' (Kirch 1986) of Polynesian dispersals, this second model postulated that the Marquesas were the first eastern archipelago settled by voyagers from West Polynesia. Successive dispersals radiated out from this 'homeland' to the Society Islands and the rest of East Polynesia. The evidence here was purely archaeological, drawing on typological comparisons of excavated artefacts and radiocarbon dates, with very little (in comparison with later research) speculation or assumptions made about expected patterns of colonisation. Retrospectively, this conservatism is surprising, given that archaeological coverage at the time was very sparse, and that the Marquesas are some 1800 nautical miles $(3300 \mathrm{~km})$ northeast of Samoa. The questionable likelihood of such a direct voyage is elided in Emory and Sinoto's map by a subtle scale and distance transformation - the Marquesas are enlarged and drawn southward and closer to Samoa than their geographic position warrants, and the Cook Islands are not shown at all. The map reifies the model. It was, however, the chronological gap between the Lapita-era settlement of West Polynesia c. 1000 BC

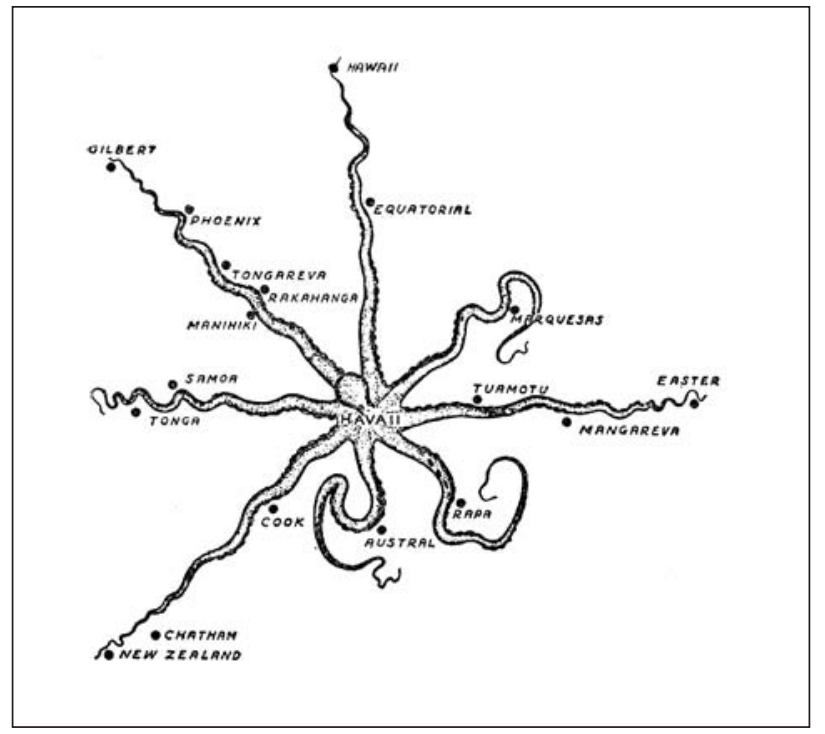

Figure 1. 'The hub of Polynesia, Havai'i, with its eight radials' (Buck 1954:88).

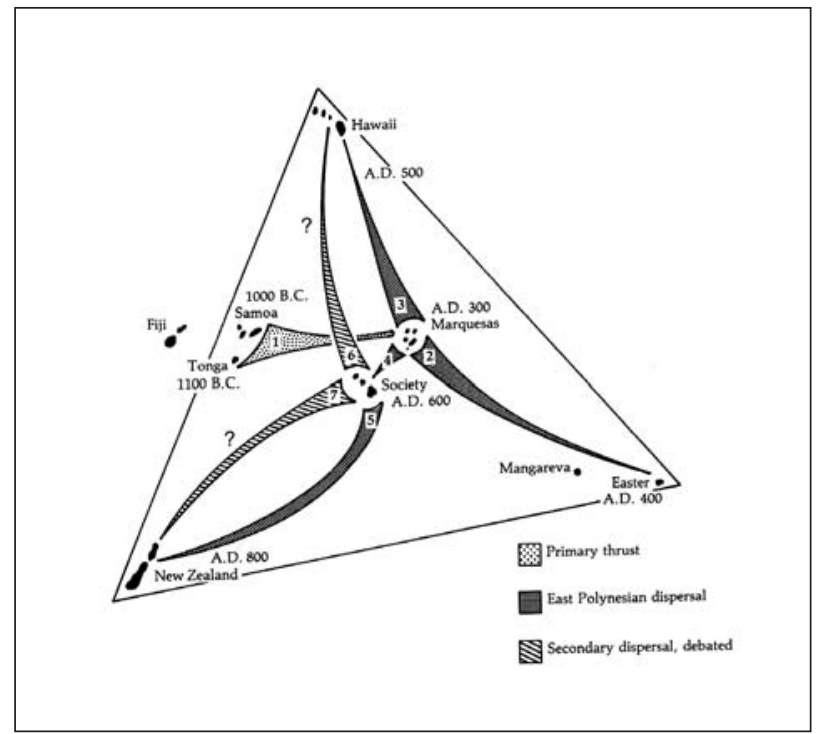

Figure 2. The 'orthodox model' of East Polynesian colonisation (Jennings 1979:3). 
and the Marquesas c. $300 \mathrm{AD}$ that drew most attention, coming to be seen as representing a problematically 'long pause' in the eastward trend of colonisation.

For Irwin (1981), the pause was an artefact of archaeological sampling - Lapita voyaging was argued to have continued on past Samoa through the southern Cooks, but archaeologists had not yet detected any settlements due to patchy fieldwork, low visibility of early sites, and environmental change. Kirch (1986) added to this a re-interpretation of the radiocarbon dates, suggesting earlier settlement of the Marquesas than originally accepted (Figure 3). These arguments sought to temporally compress the pause, framing East Polynesian colonisation as part of a continuous process of eastward movement. This was further reinforced by computer simulations arguing that no navigational threshold existed between western and eastern Polynesia (Irwin 1992:83). In the absence of early archaeological sites, positive confirmation of the scenario was sought in palaeo-environmental proxies for human impact on island environments (Kirch and Ellison 1994).

A clear epistemological shift is apparent here - this 'early-settlement' model is predictive, relying on a set of assumptions about voyaging technology and behaviour, and it appeals to logic, in contrast to the postdictive 'orthodox scenario' with its sole reliance on archaeological data. One problem, however, is that the early-settlement model is not falsifiable, since we can always argue early ephemeral sites have been destroyed and thus remain undiscovered. A critique was soon mounted, mobilised largely by Atholl Anderson, and grounded again in a more data-centred postdictive approach. The East Polynesian radiocarbon corpus was subjected to systematic screening (Spriggs and Anderson 1993), resulting in the rejection of some early dates and the proposal that the colonisation pause may have been as long as 1600 years a 'late-settlement' model. Subsequent investigation of key sites in East Polynesia supported the hypothesis, with the earliest sites in the Marquesas now dated to about 900 BP (Rolett and Conte 1995; Rolett 1998; Anderson and Sinoto 2002), the Society Islands about 1000 BP (Anderson et al. 1999), Easter Island (Rapa Nui) and Hawaii soon after (Steadman et al. 1994; Athens et al. 1999), and New Zealand about 800 BP (Anderson 1991; Higham et al. 1999). In addition, the accuracy and stacked assumptions of palaeo-environmental modelling (i.e. pollen signatures as a proxy for environmental change are a proxy for human impact) have been subjected to critique (Anderson 1995, 2002; McGlone and Wilmshurst 1999), as has the use of the performance characteristics of replica Polynesian voyaging canoes made with modern

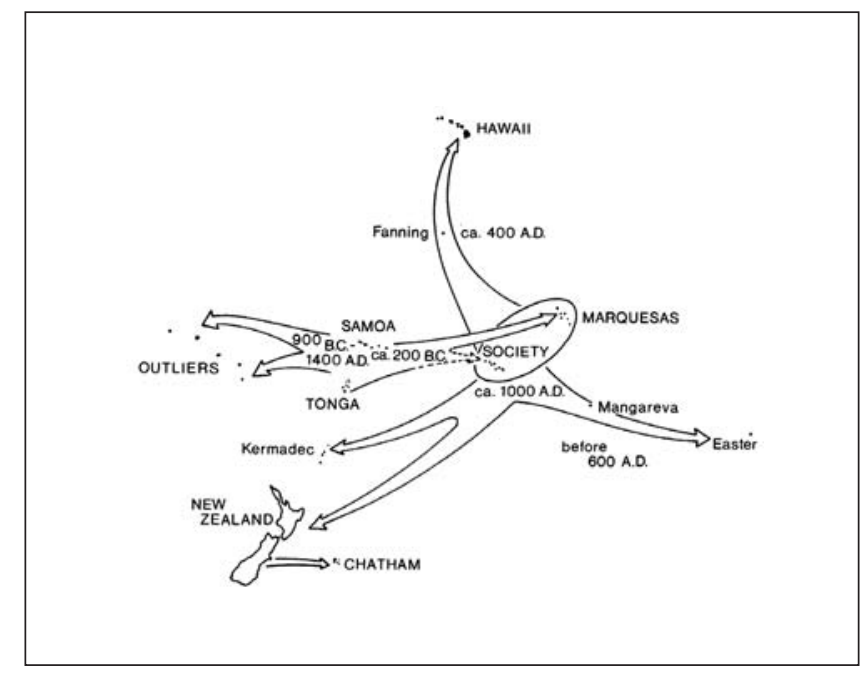

Figure 3. The early-settlement model (Kirch and Green 1987:Figure 3). 
materials for assumptions about the pace and difficulty of reaching various island targets beyond West Polynesia (Anderson 2000, 2001a).

Again, there is an epistemological quandary in this late-settlement model, for while it is potentially falsifiable (by the discovery of an older-than-anticipated site), it is not easily proven, given the nature of archaeological data. Nevertheless, in the absence of unequivocal evidence for early settlement, the late-settlement model can be regarded as currently favoured. Its acceptance requires a new map of colonisation - a pulse model (Figure 4) in which eastward migrations were episodic and punctuated by long periods of spatial stasis (Anderson 2001b). This pattern begs explanation, but this is somewhat more difficult than for the early-settlement model. The assumption of the latter is that voyaging was continuous across the Pacific, with the timing of island discoveries determined largely by geographic patterning and island size - modelled as the relative accessibility of islands to voyagers (Irwin 1992) - and a strategy of preferential upwind voyaging (Irwin 1989), or at least of waiting for seasonal westerly reversals of prevailing winds (Buck 1954:64; Finney et al. 1989). The pulse model, on the other hand, requires explanation for each pause, and also for each renewed burst of migration. Anderson (2001b:15) argues the underlying shaping factor was probably demographic rhythms, but it is clear we do not yet know enough about the role of demography in Pacific colonisation (cf. DiPiazza and Pearthree 1999).

Other large-scale factors might include the patterning of millennial-scale variations in the El Niño-Southern Oscillation (ENSO), with periods of increased westerly wind reversals correlating tolerably well with the radiocarbon chronology of colonisation pulse periods (Anderson et al. 2006). This hypothesis in itself relies on there being significant difficulties in sailing against the prevailing winds using prehistoric voyaging technologies. Consequently, the influence of small-scale technological developments may also be important, with each new pulse perhaps representing the surmounting of a previous boundary. The colonisation of East Polynesia, for example, which requires more direct travel against the prevailing winds for longer periods than is the case in Melanesia, may only have been possible with the development of the double-hulled canoe (Anderson 2001a; Anderson et al. 2006:2).

This point bears some examination because it challenges the assumptions of earlier advocates of the continuous-voyaging model. Irwin (1992:83) argued that the most difficult voyage faced during the Lapita period was between central Vanuatu and Fiji - a distance of $500 \mathrm{~nm}$ and a target angle of $21^{\circ}$ - which was considered not significantly easier than a voyage from Samoa to the southern Cooks, a distance of $630 \mathrm{~nm}$ and a target of $15^{\circ}$. This somewhat understates the difference, however, since southern Vanuatu is only $410 \mathrm{~nm}$ from Fiji (i.e. West Futuna to Viti Levu), and Viti Levu is relatively easy to detect, given that it is theoretically visible up to $50 \mathrm{~nm}$ offshore due to its height. Furthermore, during the Austral winter, such a voyage sails at some $90^{\circ}$ to the prevailing winds, allowing near peak speed and a straight-line voyage,

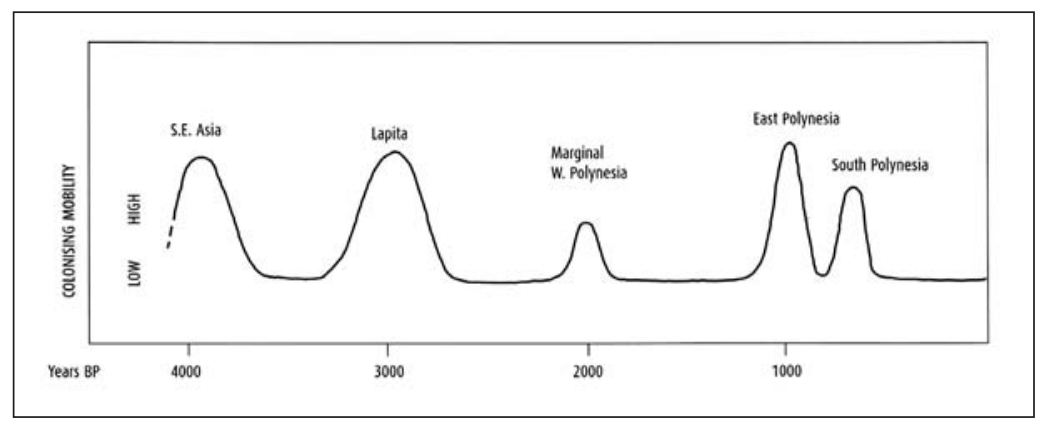

Figure 4. Anderson's (2001b) 'pulse model' or late-settlement model. 
whereas the trip from Samoa to the southern Cook Islands is directly into the prevailing winds, requiring tacking (thus increasing the distance travelled fourfold), or the arrival of fortuitous wind reversals (Finney et al. 1989:262-264). Recent computer simulations by Di Piazza et al. (2007) using accurate weekly wind data and generous canoe-performance capabilities (canoes able to sail up to $75^{\circ}$ off the wind) highlight this difference. Voyages within the region of Lapita settlement occurred over routes with arcs of success greater than $20^{\circ}$ for much of the year, while voyages to islands east of Samoa have arcs of success rarely surpassing $10^{\circ}$, and then only for a few weeks each year. For the rest of the time, such voyages are impossible (Di Piazza et al. 2007:1223-1225). The implication is that there was a significant requirement for increased accuracy of navigation and knowledge of seasonal wind patterns beyond West Polynesia.

To some extent, however, Irwin's argument that the navigational difference was not significant enough to warrant a pause of more than 1000 years still stands. Statistically, a boundary that is barely permeable will still be crossed given enough time: even if voyages to the southern Cooks were only viable for three weeks of every year, that amounts to 92 years of continuous possibility in a 1600-year period. Stochastic events are not well accounted for in current voyaging models relying on computer simulation - Buck (1954:64) gives the example of the missionary John Williams, who, on catching a favourable wind, once sailed from Samoa to the Cook Islands on a straight course without changing tack (see Williams 1837:360). In that case, the destination and distance were known, and the likelihood of such a voyage being involved in colonisation may be very small, but exactly how small is rarely estimated. Ultimately, simulation models address the question of the long pause as a matter of probability given certain static technological parameters - thus geography is their primary determining variable. A more conservative approach might be to take the longest, most difficult voyage achieved during the Lapita era as a standing technological threshold for that period - that is, only voyages less than $410 \mathrm{~nm}$, reaching targets with success arcs greater than $20^{\circ}$ and which are accessible for most of the year should be considered feasible. This, at least, is demonstrable by actual archaeological data. We could then consider any voyage beyond this threshold as representing some technological innovation in the form of higher-performance canoes, accurate navigation, or increased endurance, however incremental. The fact that the best-performing double-hulled canoes modelled by Di Piazza et al. (2007) are still rarely able to reach distant eastern targets given the wind conditions is perhaps enough to suggest that further consideration of the role of technological developments in the long pause is warranted.

What these debates make evident is the true complexity of attempting to comprehend human dispersals as an archaeological phenomenon. This can be highlighted further by considering the nature of colonisation as a process encompassing various temporally ordered components. For example, we can at minimum separate the initial discovery of an island from its settlement, and from the final establishment of a long-term community (cf. Graves and Addison 1995). Thus some small, inaccessible islands may well have been reached occasionally, but were not occupied long enough to leave an archaeological trace. Niue, for example, is $255 \mathrm{~nm}$ from Lifuka in Tonga - within the threshold for Lapita-era voyages - but was not settled until c. 2000 BP, perhaps due to its isolation and comparatively depauperate environment (Walter and Anderson 2002). So the probability of voyages at or near the limit of extant technological bounds may be weighted according to the attractiveness of the destination: the islands of Fiji are a much more rewarding reason for a long voyage than Niue. I would argue that a truly holistic model of colonisation as a process requires an account of the interaction of socio-cultural, technological, environmental and demographic factors operating differently at different periods (Figure 5). Ultimately, our ability to produce a convincing explanation or understanding of the patterning and pace of 


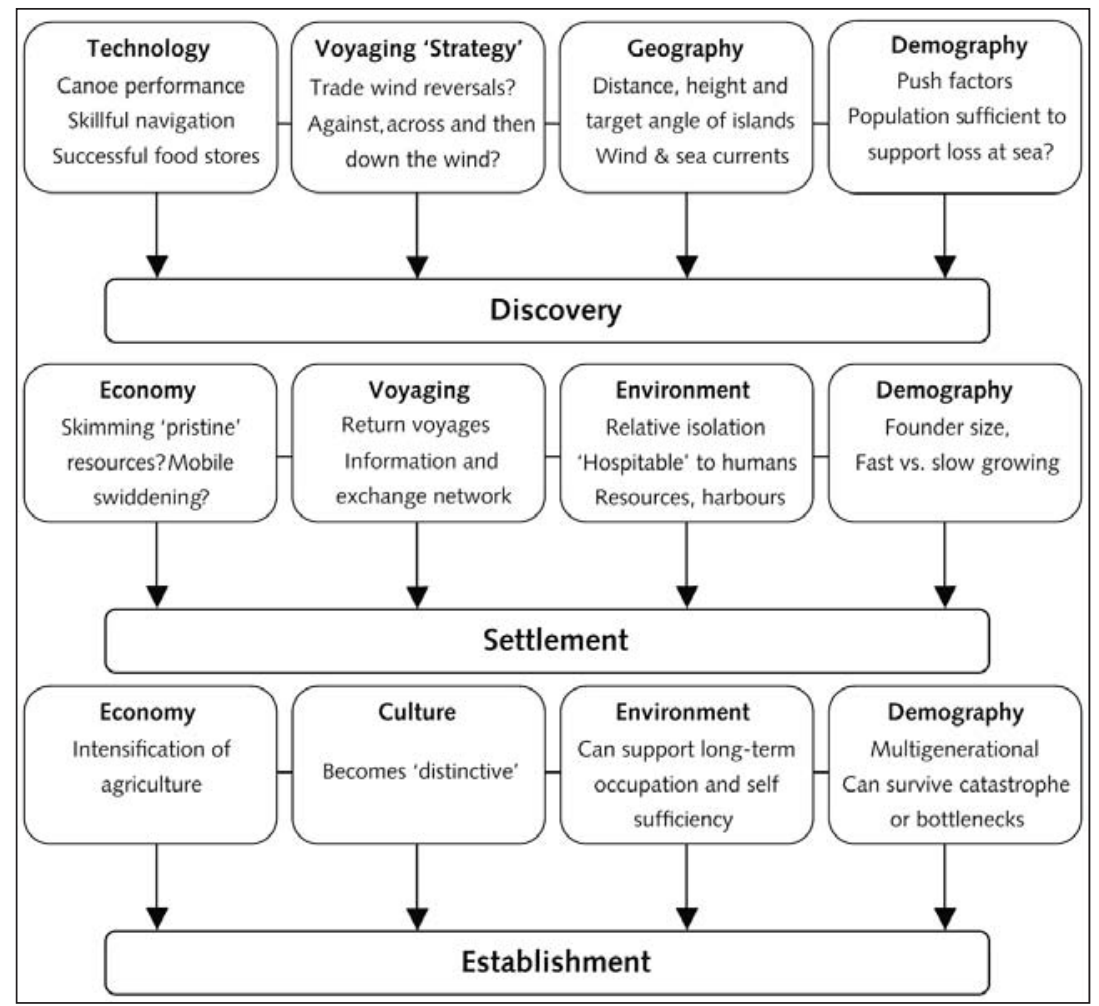

Figure 5. The colonisation process (Thomas 1997).

island settlement, as measured by radiocarbon dating, will require explicit consideration of how these factors are linked. In the remainder of this paper, I argue that one way of achieving this linking is to think about the colonisation process within the frame of the concept of 'landscape' as a cultural product (Bender 1993; Gosden and Head 1994; Tilley 1994). By way of example, I use the concept as a way of beginning to assess the role of island environments in shaping the pace of transitions between components of the colonisation process.

\section{The landscape of colonisation}

Ingold (1992:49-51) has argued that we can think of all human-experienced landscapes as an embodiment of past activity, as 'works in progress' created over generations. He stresses the role of practical action or the everyday deployment of technical skills (informed by gradients of power, ideology etc) as being the means through which we come to perceive landscapes, to know them, or to interpret parts of them within the framework of our experience. It is through such practical 'taskscapes' (Ingold 1993) that cultural landscapes are 'built' over time and subsequently inherited. This, in a nutshell, is the process of colonisation theorised. Taking the long view, the entire history of human movement into the Pacific involved just this productive encounter - a landscape, a seascape, interpreted and domesticated by experience via the socially informed technical skills of voyaging, land clearance, food gathering and production - a result of the processes plotted in Figure 5, encompassing all of its variables (see also Thomas 2001).

Given this, it might be assumed that the archaeological record of island colonisation offers a unique opportunity to study landscape encounters from their beginnings. But this is not so. Movement to a new place does not result in total change, nor complete structural transformation. Polynesian landscapes can be thought of as 'transported', not only in the usual sense of brought domesticates, but also in a conceptual sense, whereby the practical knowledge engendered in past landscapes is brought to new ones. This still allows us to think of landscapes in terms of 
difference. We may ask how each newly discovered island was different from those perceived through technically informed activity in the past, or what elements were previously unknown. A key part of understanding the colonisation of East Polynesia is therefore to be found in the environments and social structures of the west before 1000 BP. Experienced differences may be reflected in such things as geology, biota, climatic variation, isolation and so on - all elements of landscape. Upon discovery, differences such as these would gradually be encompassed through skilled action, perhaps in the form of experimentation or technical development. Monitored action, or what Giddens (1981:19) calls 'bounded knowledgability', forms the basis for making decisions, and it would be this kind of partial experience that influenced decisions such as whether to establish settlement in a specific locale.

The problem for us is how to model this process, or how to visualise and analyse it. We need to balance and evaluate the interaction of extant technologies, environmental characteristics, social patterns of access and control, and cultural preferences. Here, I want to focus on only one specific element - the modelling of how environmental difference was experienced and how this might have influenced the duration of the 'long pause'. To what extent did encounters with new landscape elements east of Fiji/Tonga/Samoa delay settlement or cause 'friction' to the colonisation process? Is it possible to quantify this? Irwin (1992) has modelled the role accessibility may have played after the islands of Polynesia were encountered - showing how increasing isolation and decreasing target size is correlated with later settlement or short-term occupation - but as yet, there have been no attempts to extend this to other elements of the experiential geography of the Pacific.

My first step is to compile a dataset of environmental variables that seeks to show similarities and differences between islands. This will then serve as a basis for comparative analysis. The most parsimonious and useful variables here include island area, geological formation, height, rainfall and isolation. Each of these has been demonstrated to play a role in the biogeographically determined diversity of an island environment. MacArthur and Wilson's (1967) theory of island biogeography famously used island area as a surrogate for environmental diversity, but this can be profitably extended via the other variables. For example, the effects of area on biodiversity are most relevant in the case of high volcanic islands which show more variation with area than do homogenous low-lying atolls (Stoddart 1992:283, 287). The main constraints on atoll diversity are thought to be ecological - that is, related more to the amount of rainfall and the frequency of drought than to area. The relationship is recursive, however, in that larger, higher islands may receive orographic rainfall and are more able to support a fresh-water lens - islands smaller than about nine hectares are essentially beaches. Isolation, too, has an effect on diversity, in that oceans are effective barriers to species transfer (Cox and Moore 1993:136-138), and in terms of human perception, isolation clearly has social ramifications. The complex interaction of each variable, then, is directly related to the patterning seen in vegetation, soils, topography, geology and hydrogeology throughout the Pacific. I derive my data for area, geology, height and rainfall from the Pacific Islands Yearbook (Carter 1984), except in cases where there are omissions, in which case data was generated from the GSHHS world shoreline dataset (Wessel and Smith 1996), and Dale (1981). Isolation can be measured using the distance of an island from its nearest neighbour and the target angle it presents, as demonstrated by Irwin (1992). But target angle is actually a function of island size (area) and distance, and distance is an effect of actual geographic position. So I have also recorded the latitude and longitude values for the centre of each island.

Differences in this dataset can be illuminated using the statistical procedure of multidimensional scaling (MDS), which is designed to analyse dissimilarity data - data that indicate the 
degree of dissimilarity (or similarity) between things. MDS analyses dissimilarity data in a way that displays their structure as a geometrical picture or 'map'. In MDS, each object (an island in this case) is represented by a point in multidimensional space, so that the (Euclidean) distances between pairs of points have the strongest possible relation to the similarities among pairs of $o b$ jects. MDS thus produces a map of the locations of objects relative to each other from data that specify how different the objects are (Kruskal 1971). Goodness-of-fit is evaluated using the stress measure, which amounts to the sum of squared deviations of observed distances from expected distances. Thus the smaller the stress value, the better is the fit between the distances on the produced map and the original observed distances.

The datasets of environmental variables are in the form of 'raw' data of greatly varying ranges. Consequently, it is necessary to standardise the data, and to convert the raw data into dissimilarity data in order to apply the method of MDS. In this instance, standardisation was performed as follows: standard score $=($ raw score - mean $) /$ standard deviation. Distance matrices were then generated using the cluster analysis module that comes with the STATISTICA software package for Windows. These matrices were used as the basis for analysis in the multidimensional scaling module of the same software.

As a test of the method, the data for latitude and longitude were standardised, converted to a distance matrix and then analysed in MDS. The result was an accurate map of the Pacific, with each island in its correct location relative to others (although not necessarily oriented according to geographical map conventions of north at the top, and east to the right). Thus, theoretically at least, the addition of any combination of the other variables would result in the spatial position of each island being transformed according to how similar or different it is from all other islands. For example, if two islands were of similar size, they would be placed closer than their true geographical position, and if of different size, they would appear further apart. The latter is demonstrated in Figure 6. Here, the islands of Viti Levu and Vanua Levu in Fiji are depicted much further away from other islands in West Polynesia due to their disproportionate size, while the majority of central Polynesian islands are compressed together, and the smaller, isolated mystery islands are scattered on the outskirts. This map is not, however, particularly informative, since the latitude and longitude variables clearly have the greater influence. If we are to understand the environmental differences encountered as voyagers moved from west to east, we need to remove these variables.

Figure 7 is an MDS analysis of all recorded environmental variables for 68 islands selected for their representativeness and access to complete data. The island of Viti Levu has been removed from the analysis because it is an outlier that compresses the scatter - on this map, it would have occupied a position far to the right of Vanua Levu (the same is true for New Zealand and Hawaii). Islands that are close together on the map are very similar in terms of the four environmental characteristics, while differences in one or more of these create separations. Area, height and geology can very generally be interpreted as being represented by dimension one that is, as we travel from positive to negative values along dimension one, the area of islands decreases, the height of islands decreases, and the geology of islands shifts from continental origin through to islands made solely of coral - although there are some obvious exceptions here. Rainfall can be seen to be reflected in dimension two - negative values represent increasing dryness, while positive values represent increasing wetness.

A series of notable clusterings occur on the map. At the very bottom left there is a group of mystery islands, clustered because they are all small, low-lying, dry, coral-reef islands. The Phoenix group and islands of the Tuamotus occur slightly above this cluster. To the right of this group is the Marquesas archipelago, separated from the rest of central East Polynesia because of 


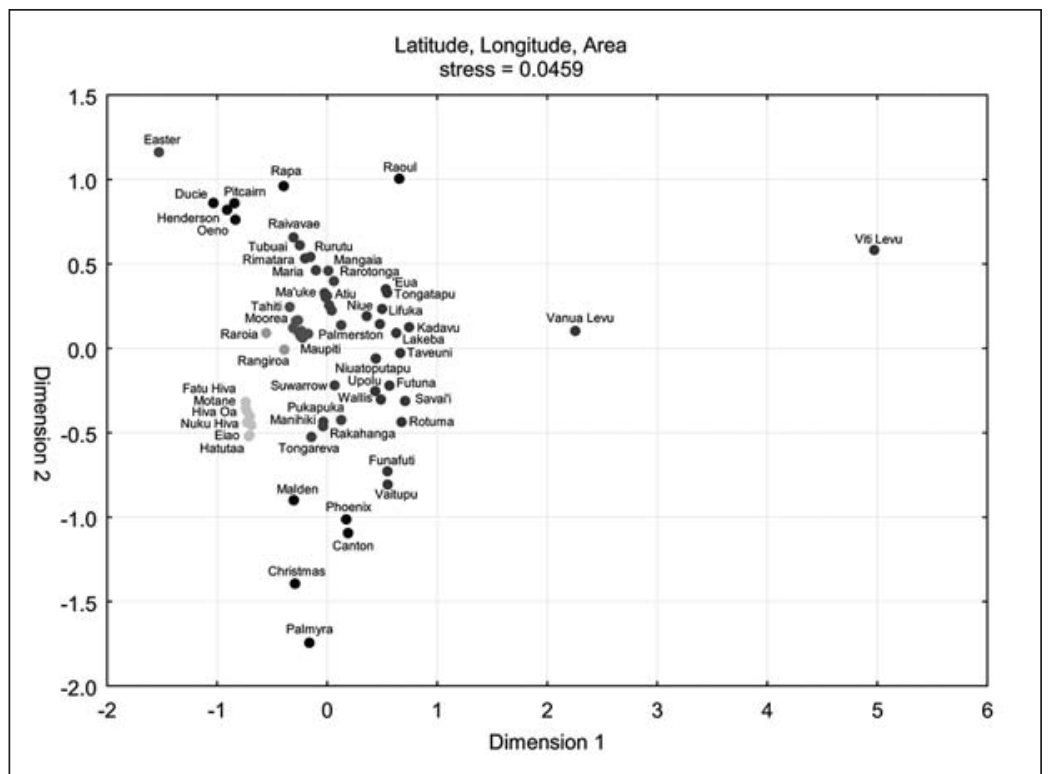

Figure 6. MDS scatterplot of 69 Polynesian islands, depicting differences in latitude, longitude and area.

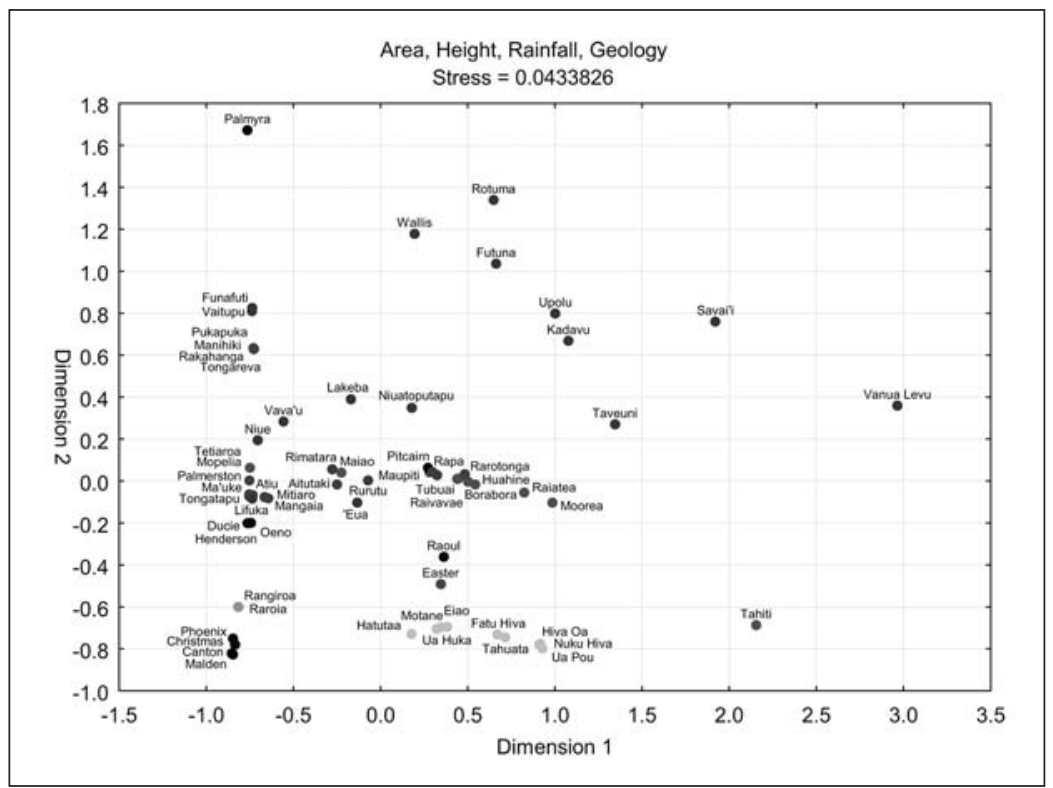

Figure 7. MDS scatterplot of 69 Polynesian islands, depicting differences in area, height, rainfall and geology.

below average rainfall. Tahiti occupies a position to the right of the Marquesas - separated from the rest of the Societies because of its size. Above these clusters is a dense band of islands with rainfall values around the mean (about $1943 \mathrm{~mm}$ per annum); a clear separation can be seen between the small coral islands and the larger volcanic islands. The western islands of Lifuka, Tongatapu and 'Eua fall within this central band, while Niue, Vava'u, Lakeba and Nuiatoputapu are located slightly above it. The next notable grouping occurs above the small central East Polynesian islands and consists of the northern Cooks and Tuvalu. Palmyra alone occupies the very top left of the map - it is one of the smallest islands, but is by far the wettest. The remaining islands occur in a spread throughout the upper right of the map, and comprise the major large islands of the West Polynesia/Fiji region. 
Approximately half of the western islands included in the analysis are noticeably different in terms of their environments from those of the eastern Pacific. Those remaining, however, express a range that is similar to the majority of East Polynesian islands. Area is not necessarily the primary differentiating variable here, since there are many small islands in West Polynesia, as was shown in Figure 6 (and many more could not be included due to lack of data). These generally have higher rainfall, however, and more importantly, are located near large continental landmasses - thus they have been colonised by a more diverse range of biota than islands to the east. Fiji, for example, has more than 300 islands, many of which are atolls and raised coral islands, but these are all located close to Vanua Levu, Viti Levu and other large continental and volcanic islands. Consequently, their soil and biota is comparatively rich. An eastward decline in biotic diversity is well documented, leading Stoddart (1992:288) to state that the most dramatic biogeographic divide is at the Tonga Trench. Stoddart (1992:282-285) also notes, however, that the environments of atolls and raised coral makatea islands are remarkably consistent throughout the Pacific.

Consequently, we can interpret the embedding of islands such as 'Eua, Lifuka and Tongatapu among the islands of East Polynesia as indicative of their general shared similarities, but it is clear there are some important differences associated with their location in relation to potential sources of propagules. Another important point is that although we can expect that prospective colonisers had experienced environmental conditions similar to those in East Polynesia before they actually arrived, such 'similar islands' occur in western archipelagos containing many different islands - including large fertile landmasses. Human experiences of place are relational and holistic, such that locations are not evaluated in isolation, but in the context of other locales nearby - thus resource-poor islands adjacent to comparatively rich landmasses would be experienced differently than if they were isolated. Figure 7 indicates that the total range of environments in the western Pacific far exceeds that of East Polynesia - all of the East Polynesian islands cluster very tightly within a smaller range than the spread-out western islands. The problem facing the colonisers of East Polynesia, then, was perhaps not one of unfamiliar environments per se; rather, it may have been that there was in effect no relief from poorer environments in the form of nearby large, fertile islands. This issue is, however, a matter of scale. It is true the total range of environments is more limited in East Polynesia, but this does not mean to say there is an unrelenting sameness. All of the major central archipelagos contain a variety of island types, and for many, this includes larger volcanic islands. We can expect these central archipelagos posed less of a challenge to a way of life than more uniform, resource-poor islands, such as the Line Islands, the northern Cook Islands, Easter Island and the Kermadecs, among others. Figure 7 depicts these latter groups clearly separated from both central East Polynesia and the western islands. The Marquesas is an interesting case. Closer on Figure 7 to Easter and Raoul than anything else, the group is revealed to be noticeably different. Although an archipelago, the Marquesas islands are particularly dry and have rugged terrain. Additionally, their isolation, deep seas and runoff from steep valleys prevent the formation of any continuous fringing reef. These factors must have been significant differences compared with the abundant coral flats of the west.

Figure 8 compares the islands of the western Pacific with their nearest eastern neighbours - the Cook Islands. The grouping here clearly shows that the majority of the Cook Islands are either very different from the majority of western islands, or at least are to be counted among the smaller, lower and dryer of the coral islands in the west. It is worthwhile noting that Lapita sites occur on Niuatoputapu, Lakeba and Tongatapu, which are all located within the environmental range of various islands in the Cooks. Taken alone, this would seem to indicate that the larger 
islands of the southern Cooks may have posed few problems for immediate settlement during the Lapita era. Many Lapita sites in the western Pacific are located in coastal and lagoon-edge environments, usually on raised coral platforms and marine terraces (Green 1979:32) - all quite common in the southern Cooks. Crucially, however, the mutual accessibility between these regions is not great (see above). Taking into account colonisation from the west, the Cook Islands were unusually isolated from other islands occupied at that time. From this perspective, we could describe the Cook Islands as being, in an environmental and spatial sense, 'extremely marginal West Polynesia' - the bottom of the barrel in terms of islands expected to be settled. As noted above, the timing of settlement on Niue in the post-Lapita period is indicative of the difference that environmental marginality coupled with isolation makes.

The remaining islands of the Cooks are, for the most part, very small atolls - many of these islands are little more than raised beaches, and it is hard to see how these would have attracted early settlement. Many of them may have only recently emerged during the initial stages of human movement into the remote Pacific (Woodroffe et al. 1990; Kerr 2003). The poverty of their land area and resources is reflected in the fact that Palmerston and Suwarrow had been abandoned by the time of European contact.

The MDS maps demonstrate that there may have been some friction to movement into East Polynesia caused by the comparative marginality of island environments. But drawing any conclusions about how this may have affected the pace of colonisation is very difficult. We can compare, however, the dating of colonisation provided by archaeological data with the environmental data in a direct way. Consider the following contour plots. Figure 9 plots the latitude and longitude of several Pacific islands against their date of first settlement, as documented by the most conservative interpretation of the radiocarbon corpus (see above for references). The contour lines on the map consequently represent the speed of human movement into the remote Pacific. Most relevant here is the general slowing of the pace of colonisation towards West Polynesia, and the compression of contour bands before Rarotonga is reached. This is the 'long pause'. Much of East Polynesia, on the other hand, is contained within a relatively

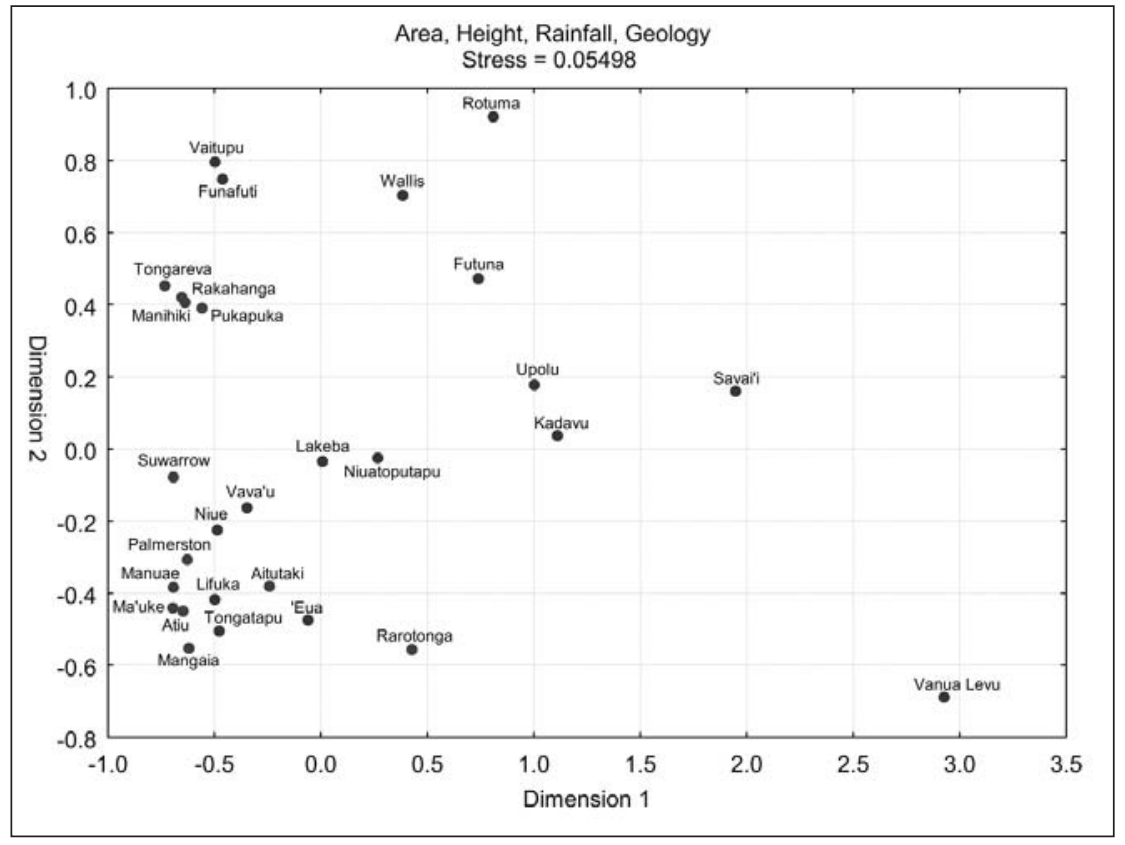

Figure 8. MDS scatterplot of West Polynesian islands compared with the Cook Islands, depicting differences in area, height, rainfall and geology. 


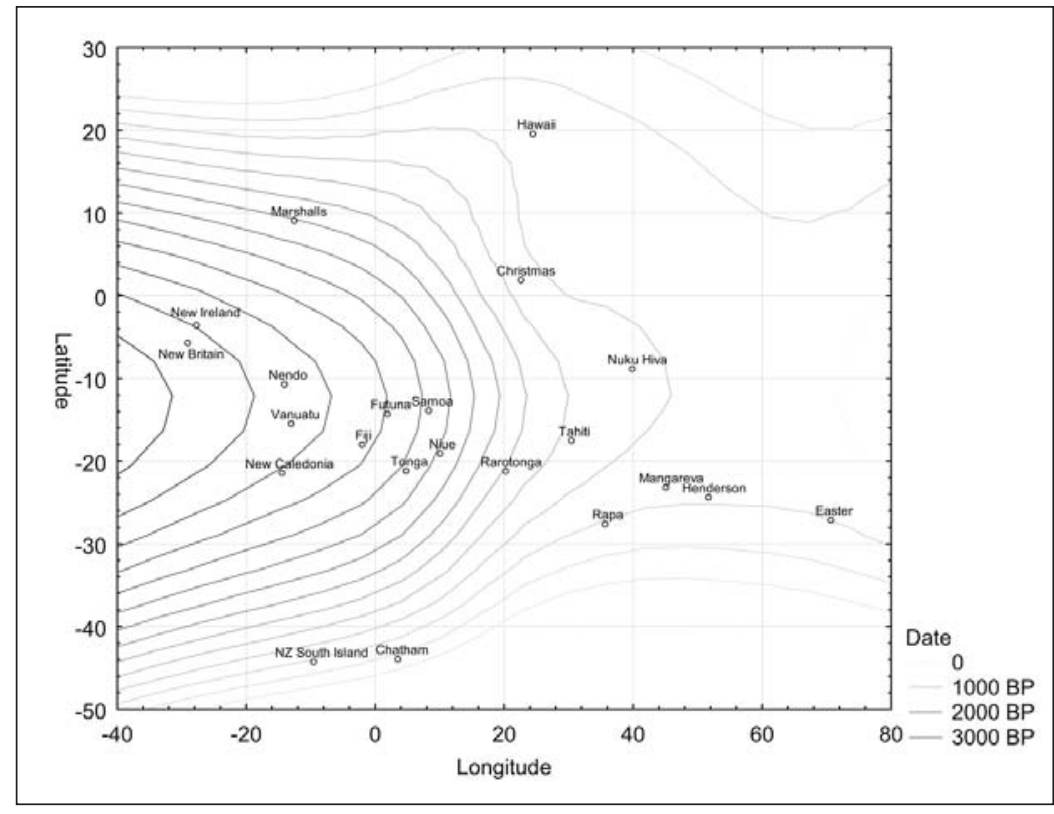

Figure 9. Contour plot showing dates of island colonisation postLapita. Date contours smoothed with distance weighted least squares method.

'flat' area, indicating the rapidity of settlement once the boundary was crossed - a massive area covered in a very short time. This is a sudden last pulse (though note the compression of contours beyond New Zealand towards marginal South Polynesia).

Figures 10-12 are similar contour plots depicting the gradients of change in island area, height and rainfall. Island area is seen to decrease rapidly east of West Polynesia, before flattening off throughout central East Polynesia. To a slightly lesser extent, the same pattern emerges for island height and the amount of rainfall experienced. There are clear subtle variations in the pattern, but generally these maps can be taken to demonstrate a rapid decline in biodiversity east of West Polynesia, resulting in a restriction of island environments in terms of their range. More to the point, this clearly correlates with the pattern seen in the dating of colonisation. The long pause in colonisation progress east of West Polynesia is paralleled by the decline in size, height and average rainfall experienced in the same region. The sudden rapidity of colonisation once this boundary was crossed is also paralleled by the uniformity of island environments encountered. In terms of a friction landscape, then, we might say that the boundaries of West Polynesia represent a steep increase in resistance to movement, but once this was overcome, friction was reduced to zero.

\section{Conclusion}

The island landscapes of the Pacific were gradually encompassed through time, during movements that required the development and deployment of skills sufficient to overcome unimagined conditions. The somewhat crude analyses produced here indicate that the pulse-like model documented by Anderson (2001b) is partially correlated with this process, with the pace of encompassment tied to gradients of environmental difference. As Lapita colonists reached Fiji/ Samoa/Tonga, they encountered islands that were smaller, more isolated and less environmentally diverse that those further west near their proximal origins. In comparison with East Polynesia, however, the islands of Fiji/Samoa/Tonga occur in dense clusters with much diversity, with large, rich islands in close proximity to more marginal atolls and raised reefs. We might imagine that early settlers took advantage of this proximity, growing gradually accustomed (or 'adapting') to the landscapes of these marginal environments in the midst of greater 'support groups'. The colonisation of Niue nearly 1000 years after the Lapita colonisation of Tonga, and then central 

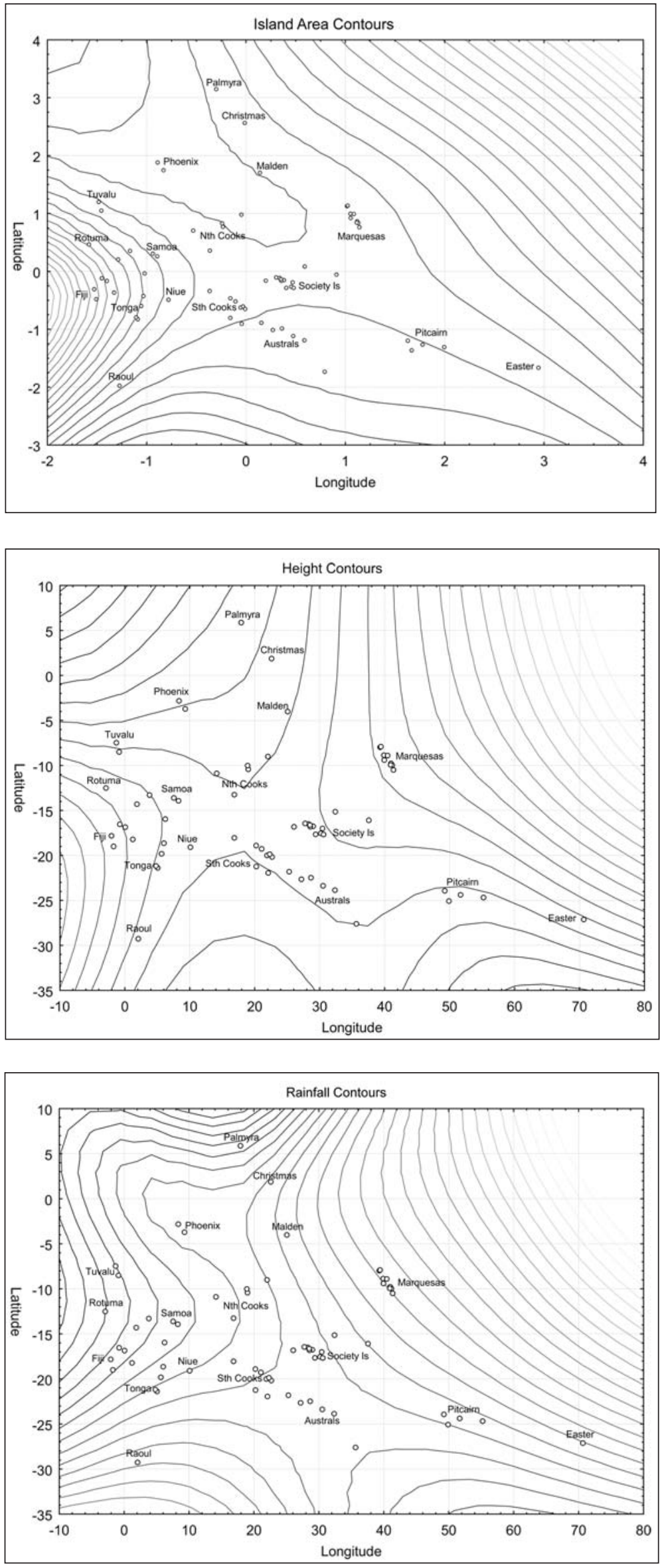

Figure 10. Contour plot showing island area. Contours smoothed with distance weighted least squares method.

Figure 11. Contour plot showing island height. Contours smoothed with distance weighted least squares method.

Figure 12. Contour plot showing average annual rainfall. Contours smoothed with distance weighted least squares method. 
East Polynesia some time after that, is perhaps indicative of a new ability to confidently dwell in such landscapes permanently, a refinement of maritime and terrestrial skills and technology that took some time to acquire. As demonstrated in the above maps, central East Polynesia contains relatively homogenous groups of islands that are more similar to each other than to the islands of West Polynesia - as a whole, they present a narrow environmental niche. The speed with which East Polynesia was settled is probably linked to this phenomenon - their uniformity presented no friction to colonisation after human learning and knowledge encompassed the challenges of the new landscape. The great distances separating the archipelagos of the east are perhaps less relevant than the smallness of the islands within them, because the amount of land settled is but a tiny fraction of that settled during the Lapita era. To some extent, this answers Kirch's (2000:232) critique of the late-settlement model on the grounds that its rapidity would require massive fertility and population increase. Clearly, with a 1600-year-long pause in West Polynesia, source populations had plenty of time to grow large, and it would perhaps not take a great many people to populate the much smaller islands of the east. Nevertheless, the question bears more examination.

Environmental and population modelling address only a small part of the process of colonisation, as does the study of modes of travel (canoes and navigation). Ultimately, we will need to bring the many different forces in play together to fully comprehend the pattern and pace of colonisation in the Pacific. I have argued that one way of beginning to address this is to begin with a theoretical perspective whereby colonisation is understood to include a process of socially, technically, economically and demographically informed engagements with the world, resulting in a gradual process of domestication of the unknown - a production of landscape. This stresses the geographic nature of colonisation experience, but is fundamentally holistic in that it expresses the wider forces shaping human behaviour. With Polynesian colonisations, we have an opportunity to understand the processes by which humans make landscapes out of environments, the way 'nature' is appropriated and encultured, and more importantly, the reasons behind this and the meanings that the processes have for the people involved. This will most certainly require much more sophisticated analyses than I have presented here, but it is worth aiming for.

\section{Acknowledgments}

Some of the material presented here was first developed during the production of my MA thesis in the mid-1990s, at a time when debates about Polynesian colonisation were at their peak. I owe my decision to write about the topic to Atholl Anderson, Helen Leach and Richard Walter who, through undergraduate (AA) and postgraduate (HL) lectures, and during fieldwork discussions (RW) encouraged my interest. Richard Walter supervised my MA, and was the first to suggest using MDS as a method. 


\section{References}

Anderson, A. 1991. The chronology of colonization in New Zealand. Antiquity 65:767-795.

Anderson, A. 1995. Current approaches in East Polynesian colonisation research. Journal of the Polynesian Society 104:110-132.

Anderson, A. 2000. Slow boats from China: issues in the prehistory of Indo-Pacific seafaring. In

S. O'Connor and P. Veth (eds), East of Wallace's Line: studies of past and present maritime cultures of the Indo-Pacific region, pp.13-50. Amsterdam: Balkema.

Anderson, A. 2001a. Towards the sharp end: the form and performance of prehistoric Polynesian voyaging canoes. In C.M. Stevenson, G. Lee and F.J. Morin (eds), Pacific 2000: proceedings of the fifth international conference on Easter Island and the Pacific, pp. 29-36. Los Osos: Easter Island Foundation.

Anderson, A. 2001b. Mobility models of Lapita migration. In G. Clark, A. Anderson and T. Vunidilo (eds), The Archaeology of Lapita dispersal in Oceania, pp. 15-23.Terra Australis 17.

Anderson, A., E. Conte, G. Clark, Y. Sinoto, and F. Petchey 1999. Renewed excavations at Motu Paeaeo, Mapiti Island, French Polynesia: Preliminary Results. New Zealand Journal of Archaeology 21:47-65.

Anderson, A.J. and Y.H. Sinoto 2002. New radiocarbon ages of colonization sites in East Polynesia. Asian Perspectives 41:242-257.

Anderson, A.J., J. Chappell, M. Gagan, and R. Grove 2006. Prehistoric maritime migration in the Pacific islands: An hypothesis of ENSO forcing. Holocene 16:1-6.

Athens, J., J. Ward, H. Tuggle and D.Welch 1999. Environment, Vegetation Change and Early Human Settlement on the 'Ewa Plain: A Cultural Resource Inventory of Naval Air Station, Barber's Point, O'ahu, Hawaìi. Part III: Palaeoenvironmental Investigations. Honolulu: International Archaeological Research Institute Inc.

Bender, B. (ed) 1993. Landscape: politics and perspectives. Oxford: Berg.

Bateson, G. 1972. Steps to an ecology of mind: collected essays in Anthropology, Psychiatry, Evolution, and Epistemology. London: Chandler.

Buck, P. 1954. Vikings of the Sunrise. Christchurch: Whitcombe and Tombs.

Carter, J. (ed) 1984. Pacific Islands Yearbook, 15th edition. Sydney: Pacific Publications.

Carter, P. 1987. The road to Botany Bay: an essay in spatial history. London: Faber and Faber.

Cox, C.B. and P.D. Moore 1993. Biogeography: an Ecological and Evolutionary Approach. Oxford: Blackwell Scientific Publications.

Dale, W.R. (ed) 1980. Pacific Island Water Resources. Wellington: DSIR.

Di Piazza, A. and E. Pearthree 1999. The spread of the 'Lapita People': A demographic simulation. Journal of Artificial Societies and Social Simulation 2(3):1-15.

Di Piazza, A., P. Di Piazza and E. Pearthree 2007. Sailing virtual canoes across Oceania: revisiting island accessibility. Journal of Archaeological Science 34:1219-1225.

Emory, K.P. and Y.H. Sinoto 1965. Preliminary report on the archaeological investigations in Polynesia. Report for the National Science Foundation, Bernice P. Bishop Museum Archives.

Finney, B., P. Frost, R. Rhodes, and N. Thompson 1989. Wait for the west wind. Journal of the Polynesian Society 98:261-302.

Giddens, A. 1981. A contemporary critique of historical materialism: Power, property and the State. London: Macmillan.

Gosden, C. and L. Head 1994. Landscape - a usefully ambiguous concept. Archaeology in Oceania 29:113-116.

Graves, M.W. and D.J. Addison 1995. The Polynesian settlement of the Hawaiian Archipelago: Integrating models and methods in archaeological interpretation. World Archaeology 26:380-399.

Green, R.C. 1979. Lapita. In J.D. Jennings (ed), The Prehistory of Polynesia, pp. 27-60. Canberra: Australian National University Press. 
Green, R.C. and P.V. Kirch 1987. History, Phylogeny and Evolution in Polynesia. Current Anthropology 28:431-456.

Higham, T.F.G., A. Anderson and C. Jacomb 1999. Dating the first New Zealanders: the chronology of Wairau Bar. Antiquity 73:420-427.

Ingold, T. 1992. Culture and the perception of the environment. In E. Croll and D. Parkin (eds), Bush Base: Forest Farm - Culture, Environment and Development, pp. 39-56. London: Routledge.

Ingold, T. 1993. The temporality of the landscape. World Archaeology 25:152-174.

Irwin, G. 1981. How Lapita lost its pots: the question of continuity in the colonisation of Polynesia. Journal of the Polynesian Society 90:481-494.

Irwin, G. 1992. The prehistoric exploration and colonisation of the Pacific. Cambridge: Cambridge University Press.

Jennings, J.D. (ed) 1979. The Prehistory of Polynesia. Canberra: Australian National University Press.

Kerr, R.A. 2003. Pacific migration arrested by meltdown's high waters. Science 302:1888-1889.

Kirch, P.V. 1986. Rethinking East Polynesian prehistory. Journal of the Polynesian Society 95:9-40.

Kirch, P.V. and J. Ellison 1994. Palaeoenvironmental evidence for human colonization of remote Oceanic islands. Antiquity 68:310-321.

Kruskal, J.B. 1971. Multidimensional scaling in archaeology: Time is not the only dimension. In F.R. Hodson, D.G. Kendall, and P. Tautu (eds), Mathematics in the Archaeological and Historical Sciences, pp. 119-132. Edinburgh: Edinburgh University Press.

MacArthur, R.H. and E.O. Wilson 1967. The theory of island biogeography. Princeton: Princeton University Press.

McGlone, M. and J. Wilmshurst 1999. Dating initial Maori environmental impact in New Zealand. Quaternary International 59:5-16.

Rolett, B.V. 1998. Hanamiai: Prehistoric Colonization and Cultural Change in the Marquesas Islands (East Polynesia). New Haven: Publications in Anthropology, Yale University.

Rolett, B.V. and E. Conte 1995. Renewed Investigation of the Ha'atuatua Dune (Nukuhiva, Marquesas Islands): A key site in Polynesian prehistory. Journal of the Polynesian Society 104:195-228.

Spriggs, M. and A. Anderson 1993. Late colonisation of East Polynesia. Antiquity 67:200-217.

Steadman, D., P.Vargas and C. Cristino 1994. Stratigraphy, chronology and cultural context of an early assemblage from Easter Island. Asian Perspectives 33:79-96.

Stoddart, D.R. 1992. Tropical Pacific biogeography. Pacific Science 46:279-293.

Thomas, T. 1997. The practice of colonization in East Polynesia. Unpublished MA thesis, Anthropology Department, University of Otago.

Thomas, T. 2001. The social practice of colonisation: Re-thinking prehistoric Polynesian migration. People and Culture in Oceania 17:27-46.

Tilley, C. 1994. A phenomenology of landscape: Places, paths and monuments. Oxford: Berg.

Walter, R. and A. Anderson 2002. The Archaeology of Niue Island, West Polynesia. Bishop Museum Bulletins in Anthropology 10.

Wessel, P. and W. Smith 1996. A global self-consistent, hierarchical, high-resolution shoreline database. Journal of Geophysical Research 101:8741-8743.

Williams, J. 1837. A Narrative of missionary enterprises in the South Sea Islands. London: J. Snow.

Winkler, Captain. 1901. On sea charts formerly used in the Marshall Islands, with notices on the navigation of these islanders in general. Smithsonian Institute Report for 1899 54:487-508.

Wood, D. 1992. The power of maps. New York: The Guildford Press.

Woodroffe, C.D., D.R. Stoddart, T. Spencer, T. Scoffin, and A. Tudhope 1990. Holocene emergence in the Cook Islands, South Pacific. Coral Reefs 9(1):31-39. 